\title{
Perspective
}

\section{Ethical Agreement and Disagreement about Obesity Prevention Policy in the United States}

\author{
Anne Barnhill ${ }^{1, *}$, Katherine F. King ${ }^{2}$ \\ ${ }^{1}$ Department of Medical Ethics and Health Policy, University of Pennsylvania, Philadelphia, PA, USA \\ ${ }^{2} \mathrm{Li}$ Ka Shing Knowledge Institute, St. Michael's Hospital, Toronto, Canada \\ Received: 17 July 2013, Accepted: 13 August 2013, ePublished: 14 August 2013
}

\begin{abstract}
An active area of public health policy in the United States is policy meant to promote healthy eating, reduce overconsumption of food, and prevent overweight/obesity. Public discussion of such obesity prevention policies includes intense ethical disagreement. We suggest that some ethical disagreements about obesity prevention policies can be seen as rooted in a common concern with equality or with autonomy, but there are disagreements about which dimensions of equality or autonomy have priority, and about whether it is justifiable for policies to diminish equality or autonomy along one dimension in order to increase it along another dimension. We illustrate this point by discussing ethical disagreements about two obesity prevention policies.
\end{abstract}

Keywords

Obesity Prevention, Public Health Ethics, Food Policy, Food Tax, Autonomy, Justice

\section{Obesity prevention and ethics in the United States}

In the United States, growing concern about the negative health effects of unhealthy eating, overweight and obesity, as well as concern about the financial costs of treating diet-related illness, have prompted policy efforts to promote healthier eating. The federal government, as well as state and local governments, have proposed and implemented a variety of policies meant to increase consumption of healthy food and reduce overconsumption of unhealthy food (1-3). Policies that limit access to unhealthy food have proven especially controversial. Examples of such policies include bans on the use of trans fat in restaurants (4), nutritional requirements for fast food meals marketed as children's meals (the "Happy Meal ban") (5), policies limiting the density of fast food restaurants (6), proposals to exclude unhealthy food from food assistance programs (7), proposed taxes on sugary drinks (8), and a proposal by New York City to limit the sale of large sugary drinks (9).

Ethicists, public health experts, social scientists, and advocates have all raised ethical concerns with these policies, as well as making ethical arguments for these policies (10-14). Public discussion of these policies has often been phrased in ethical terms, using ethical concepts such as fairness, equality, respect, legitimacy, paternalism, infantilization, liberty, and freedom; the popular press articles we cite in this paper give just a few examples, and a Google search could provide dozens more. We suggest that many of the ethical arguments for and against obesity prevention policies can be seen as distinct threads of two core ethical concerns: ethical concern with individual autonomy, and ethical concern with equality. Furthermore, ethical disagreement about obesity prevention policies can be seen, in many cases, as rooted in a common concern with equality or with autonomy, but disagreement about which dimensions of equality or autonomy have priority, and disagreement about whether it is justifiable for government policies to diminish equality or autonomy along one dimension in order to increase it along another dimension. We illustrate this point by discussing ethical disagreement about two obesity prevention policies, taxes on unhealthy food and the New York City soda ban.

\section{Equality and obesity prevention policy}

Some objections to obesity prevention policies use the language of equality and fairness, and related concepts. For example, a common objection to food taxes is that they are regressive and therefore unfair (15). To give another example, proposals to exclude unhealthy foods from food assistance programs have been objected to as unfairly targeting program participants, as inequitable, demeaning, and stigmatizing (13).

The language of equality and fairness is used to capture a range of ethical concerns (13). One dimension of equality is distributive equality or distributive justice. Distributive equality is concerned with the resources and opportunities individuals have at their disposal, and the life outcomes they achieve. Certain distributions of resources, opportunities or life outcomes are considered fair, whereas other distributions are considered unfair.

Some ethical disagreement about specific policies can be seen as rooted in a common concern with distributive equality-that is, a common concern with ensuring that there is a fair distribution of resources, opportunities and outcomes-but disagreement about what it is that must be fairly distributed. In the context

*Corresponding author: Anne Barnhill; Email: anne.barnhill@gmail.com 
of obesity prevention policy, we might be concerned about a fair distribution of multiple things, including: health, income, financial access to healthy food, geographic access to healthy food, and consumer choice. The status quo is that, none of these things are equally distributed across the population in the United States. Instead, there are inequalities in health and income across racial, ethnic, and geographic groups, and inequalities between income groups in access to healthy food as well as other essential goods. Specific policies could help to create a more equal or more fair distribution of one thing (e.g. health) while exacerbating the unequal distribution of something else (e.g. income). In such cases, people might disagree about whether it is acceptable to exacerbate inequality along one dimension in order to diminish inequality along another dimension.

For example, one ethical objection to taxes on unhealthy food is that these taxes are regressive-that is, they take a larger share of the income of lower income people-and are unfair for this reason (15). Simultaneously, an argument given in favour of taxes on unhealthy food is that they will help to alleviate health disparities (i.e. the higher rates of obesity and diet-related illness among lower income people), precisely because they disproportionately impact low income people. As one proponent of taxes on soda put it, "The soda tax would help low-income residents by encouraging them to choose healthier beverages and by creating more grocery stores and jobs in low-income neighborhoods. A soda tax is a public health policy that helps improve the quality of life for low-income residents. Obesity is a regressive disease" (16). Both opponents and proponents of such taxes are concerned with the fair distribution of something, but opponents prioritize the fair distribution of income while opponent prioritize the fair distribution of health. In other words, proponents and opponents disagree about which demands of distributive equality have priority.

In our opinion, regressive taxes can be ethically justifiable, and the soda tax is a good example. Regressive taxes are ubiquitous. General sales tax, tobacco taxes, alcohol taxes, and taxes on public utilities are all taxes that take a higher percentage of the income of lower income people; tobacco taxes are especially regressive, taking seven times more of the income of the poorest $20 \%$ than the richest $20 \%$ of people (17). Flat fees for public services are also regressive. Progressive income tax compensates to some extent for specific regressive taxes, and the fact that a specific tax is regressive is not usually considered a decisive argument against it.

A notable exception is tax on groceries, a regressive tax that is widely opposed as such. Most states have no sales tax on groceries: Of the 45 states in the United States that have a general sales tax, 31 states do not levy sales tax on groceries, and seven states tax groceries at a lower rate (18). At the same time, however, most states that do not tax groceries do tax sodas, and several tax candy $(18,19)$. This pattern of taxes reveals a recognized distinction between foods that are necessities and therefore should not be subject to a regressive tax (i.e. groceries), and other things we eat, like soda, candy and restaurant food, that are clearly non-necessities and thus may be fairly subjected to a regressive tax.

\section{Autonomy and obesity prevention policy}

Just as some disagreements about obesity prevention policies are rooted in disagreement about which demands of distributive equality have priority, other disagreements are rooted in a common concern with individual autonomy but differing views about which dimensions of autonomy have priority.

Simply put, autonomy is as a self-rule (20) (of course, things are not quite this simple, as philosophers recognize multiple distinct notions of autonomy) (21). To be autonomous, one must be free of control by others, have control over oneself, and understand what one's doing. Thus being autonomous-making autonomous choices and engaging in autonomous actionsrequires being free from control by others (liberty), having the psychological capacity to make choices and act on them, and understanding the available courses of action and their effects. All three dimensions of autonomy-liberty, psychological capacity, and understanding-come in degrees. For example, the psychological capacity to make choices and act on them lies along a spectrum, from the minimal capacity to have preferences and act on them, to the capacity to make informed choices, to the capacity to build a life that conforms with one's values and goals (e.g. the goal to maintain a healthy weight and stay healthy). In the context of food and eating, there are multiple ways in which the three dimensions of autonomy-liberty, psychological capacity and understanding - can be compromised:

- Liberty/freedom from external constraints. Liberty is diminished by constraints and penalties on choice and action. Examples of such constraints and penalties are product bans and taxes.

- Understanding of the available options and how they impact one's interests. This understanding can be diminished by lack of information, as well as the confusing presentation of information in food advertising, food marketing, and food labelling (22-24).

- Psychological capacity to make choices and act on them. Our psychological capacity to control our eating, rather than eating more than we would like or eating less healthfully than we would like, can be diminished by multiple factors: psychological factors such as food addiction, social influences such as social norms encouraging overconsumption and environmental influences such as the prevalence of unhealthy food (25-28). Psychological capacity can also be diminished by the simple lack of time and energy to make the best choices.

When people have robust autonomy vis-à-vis food, this allows them to make food choices for themselves and their families that are pleasurable and healthy, that express their personal identities and cultural affiliations, and that conform with their personal values. The robust exercise of food autonomy can promote health (though of course, people may also autonomously choose to eat unhealthily), whereas diminished food autonomy can compromise health. Acting autonomously is considered ethically valuable because of its good consequences for individuals, families, communities and societies. We exercise our autonomy as individuals, as we build lives for ourselves and our loved ones, and we also exercise our autonomy as members of groups, as we together build communities and societies. But autonomy is also seen by some as a moral good in and of itself, and violating someone's autonomy is seen as a moral wrong in and of itself, whether or not it has good or bad consequences $(20,29)$.

The ethical value of food autonomy provides both ethical reasons against policies-when those policies compromise autonomy along a dimension-and ethical reasons for healthy eating policies-when those policies strengthen autonomy along a dimension. A single policy could compromise autonomy 
along one dimension while strengthening it along another; or compromise autonomy in a surface way while strengthening it in a deeper sense (20). As an example, consider the New York City big soda ban, a controversial policy passed by the New York City Board of Health but subsequently ruled unconstitutional, and hence never implemented (30). According to the ban, sodas and certain other sugary drinks larger than 16 ounces may not be sold in restaurants, corner stores, and many other food establishments in New York City (31). The ban was intended to reduce consumption of sugary drinks, thereby reducing rates of obesity and diabetes.

The ban has been criticized on multiple grounds, both empirical and practical. One strain of ethical criticism is that the soda ban would unduly restricting consumer choice, violate consumers' right to choose, and limit personal freedom (3234). By preventing sellers from offering certain products (i.e. sugary drinks larger than 16 ounces) and preventing consumers from purchasing these products, the soda ban would diminish individual autonomy along one dimension: it would diminish individual liberty and freedom from external constraint. At the same time, proponents of the soda ban could argue that it will increase individual autonomy along another dimension, by increasing individuals' psychological capacity to make good choices. As Hunter and Van Busum argue:

"When it comes to selecting a drink size, we often choose quickly and reflexively. But when we are not distracted by the option of buying a 32-ounce or larger soda, we have the chance to stop and think-just for a second-about how much we actually want. How many calories do we want to take in? How much money do we want to spend? If it turns out that what we want is 32 ounces of soda, then we can buy two 16-ounce containers. The ban on excessive single-serving beverages takes the home field advantage away from soda companies and gives consumers the opportunity to consider their real preferences. So rather than obstructing freedom of choice, the big-container ban actually enhances it" (35).

By making us pause and reflect upon our soda consumption, the soda ban could enhance our psychological capacity to make good choices about what we drink. In limiting the options available to consumers, the soda ban simultaneously reduces individual autonomy along one dimension (liberty) while perhaps bolstering autonomy along another dimension (psychological capacity). We can see some disagreement about the soda ban as disagreement about whether it is appropriate for government policy to limit autonomy along one dimension (liberty) in order to bolster it along another dimension (psychological capacity).

In our opinion, it can be ethically appropriate to limit the available consumer options in order to facilitate better decisionmaking (that is, limit liberty in order to bolster psychological capacity). It can also be ethically appropriate to limit the available consumer options in order to achieve other goods-for example, improving health or aligning consumer choices with people's long-term goals-even if these limitations do not also improve decision-making. As ethicist Sarah Conly puts it: "We do not think preserving your autonomy, your freedom to act based on your own decision, is worth the costs, in part because your decision making is done so badly that your freedom is used very poorly" (36). However, such limitations of consumer choice will have to be justified on a case by case basis, taking into account the range of ways in which limiting the consumer option has value for individuals (for example, bolstering decision-making or improving health) as well as all the ways in which limiting it has disvalue (for example, limiting liberty or preventing valuable experiences).

\section{Conclusion}

In the United States, public discussion of obesity prevention policies is often acrimonious and riven with ethical disagreement. We would like to suggest that some of these disagreements are rooted in common concern with both equality and autonomy, but there are disagreements about which dimensions of equality and autonomy have priority. Perhaps recognition of our shared ethical concerns could help us make progress on resolving the real points of disagreement that remain.

\section{Ethical issues \\ Not applicable.}

\section{Competing interests}

The author declares that they have no competing interests.

\section{Authors' contributions}

Both $\mathrm{AB}$ and $\mathrm{KFK}$ contributed to the conception and design of the manuscript. $\mathrm{AB}$ drafted the initial draft of the manuscript and both authors critically revised the final draft.

\section{References}

1. Mello MM, Studdert DM, Brennan TA. Obesity-the new frontier of public health law. N Engl J Med 2006; 354: 2601-10.

2. Silver L, Bassett MT. Food safety for the 21st century. JAMA 2008; 300: 957-9.

3. Dietz WH, Hunter AS. Legal preparedness for obesity prevention and control: the public health framework for action. J Law Med Ethics 2009; 37: 9-14.

4. Center for Science in Public Interest. Trans Fat Bans in Restaurants. Available from: http://www.cspinet.org/transfat/

5. Bernstein S. San Francisco bans Happy Meals. Los Angeles Times [serial on the Internet]. [updated 2010 Nov 2; cited 2013 Aug 1]; Available from: http://articles.latimes.com/2010/nov/02/business/la-fihappy-meals-20101103

6. Severson K. Los Angeles Stages a Fast Food Intervention. New York Times [serial on the Internet]. [updated 2008 Aug 13; cited 2013 Aug 1]. Available from: http://www.nytimes.com/2008/08/13/dining/13calo.html

7. Barnhill A. Impact and Ethics of Excluding Sweetened Beverages from the SNAP Program. Am J Public Health 2011; 101: 2037-43.

8. Brownell KD, Frieden TR. Ounces of Prevention-The Public Policy Case for Taxes on Sugared Beverages. N Engl J Med 2009; 360: 18058.

9. Grynbaum MM. Bloomberg Plans a Ban on Large Sugared Drinks. New York [serial on the Internet]. [updated 2012 May 30; cited 2013 Aug 1]; Available from: http://www.nytimes.com/2012/05/31/nyregion/ bloomberg-plans-a-ban-on-large-sugared-drinks.html

10. Holm S. Obesity interventions and ethics. Obes Rev 2007; 8: 20710.

11. Purcell M. Raising healthy children: Moral and political responsibility for childhood obesity. J Public Health Policy 2010; 31: 433-46.

12. Have MT, van der Heide A, Mackenbach JP, de Beaufort ID. An ethical framework for the prevention of overweight and obesity: a tool for thinking through a programme's ethical aspects. Eur J Public Health 2012; 23: 299-305.

13. Barnhill A, King KF. Evaluating equity critiques in food policy: the case of sugar-sweetened beverages. J Law Med Ethics 41: 301-9.

14. Kirkland A. The environmental account of obesity: a case for feminist skepticism. Signs 2011; 36: 463-85.

15. The Checkup. Is a Soda Tax Fair? Washingtonpost. [cited 2013 Aug 
2]; Available from: http://voices.washingtonpost.com/checkup/2009/08/ is_a_soda_tax_fair.html

16. Cheh M. 10 Myths About the Soda Tax. [cited 2013 Aug 2]; Available from: http://www.marycheh.com/index.php?option=com_content\&view= article\&id $=145 \&$ Itemid $=79$

17. Chamberlain A, Prante G. Who pays taxes and who receives government spending? An analysis of federal, sate and local tax and spending distributions, 1991-2004. Tax Foundation; 2007 Mar. Report No.: 1 .

18. Center on Budget and Policy Priorities. Which States Tax the Sale of Food for Home Consumption in 2009? 2009 Nov. [cited 2013 Aug 2]; Available from: http://www.cbpp.org/cms/?fa=view\&id=1230

19. Some states like the sweet taste of soda and candy taxes. Stateline [serial on the Internet]. 2010. [cited 2013 Aug 12]; Available from: http:// www.pewstates.org/projects/stateline/headlines/some-states-like-thesweet-taste-of-soda-and-candy-taxes-85899374842

20. Nys TRV. Paternalism in Public Health Care. Public Health Ethics 2008;1: 64-72.

21. Arpaly N. Varieties of Autonomy. Unprincipled Virtue. New York: Oxford University Press; 2003. p. 117-48.

22. Colby SE, Johnson L, Scheett A, Hoverson B. Nutrition marketing on food labels. J Nutr Educ Behav 2010; 42: 92-8.

23. Nestle M, Ludwig DS. Front-of-package food labels. JAMA 2010; 303: $771-2$.

24. Cowburn G, Stockley L. Consumer understanding and use of nutrition labelling: a systematic review. Public Health Nutr 2005; 8: 21-8.

25. Cohen D, Farley TA. Peer Reviewed: Eating as an Automatic Behavior. Prev Chronic Dis 2008; 5: A23.

26. Lang T, Rayner G. Overcoming policy cacophony on obesity: an ecological public health framework for policymakers. Obes Rev 2007; 8: $165-81$.

27. Van Baaren RB, Wigboldus DH. The unconscious consumer: Effects of environment on consumer behavior. J Consum Psychol 2005; 15 : 193-202.

28. Brownell KD, Kersh R, Ludwig DS, Post RC, Puhl RM, Schwartz MB, et al. Personal Responsibility and Obesity: A Constructive Approach To A Controversial Issue. Health Aff (Millwood) 2010; 29: 379-87.

29. Dworkin G. Paternalism. Monist 1972; 64-84 .

30. Reuters. Bloomberg's Ban on Big Sodas Is Unconstitutional: Appeals Court. New York [serial on the Internet]. [updated 2013 Jul 30; cited 2013 Aug 1]; Available from: http://www.nytimes.com/reuters/2013/07/30/us/ politics/30reuters-sodaban-lawsuit.html

31. Yee V. Your Guide to New York's Soda Ban. New York [serial on the Internet]. [updated 2013 Mar 11; cited 2013 Aug 1]; Available from: http://cityroom.blogs.nytimes.com/2013/03/11/your-guide-to-new-yorkssoda-ban/

32. A Soda Ban Too Far. New York Times [serial on the Internet]. [updated 2012 May 31; cited 2013 Aug 1]; Available from: http://www. nytimes.com/2012/06/01/opinion/a-soda-ban-too-far.html

33. Groups: NYC soda ban unfair to small, minority-owned businesses. CNN [serial on the Internet]. [cited 2013 Aug 1]; Available from: http:// www.cnn.com/2013/01/23/health/new-york-large-drinks/index.html 34. NYC Big Soda Ban Could End Up in Court. CSPnet.com [serial on the Internet]. [cited 2013 Aug 1]; Available from: http://www.cspnet.com/ news/beverages/articles/nyc-big-soda-ban-could-end-court 35. Hunter L, Busum and KV. Soda "Ban" May Actually Increase Freedom of Choice. Huffington Post [serial on the Internet]. [cited 2013 Aug 2]; Available from: http://www.huffingtonpost.com/lauren-hunter/ new-york-soda-ban_b_1904920.html

36. Conly S. Against autonomy: justifying coercive paternalism. Cambridge: Cambridge University Press; 2013. p.179-80. 